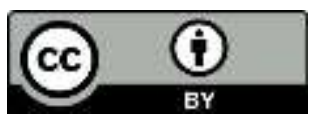

\title{
O “JEJUM DE DANIEL": A DESINTOXICAÇÃO AUDIOVISUAL DA IGREJA UNIVERSAL DO REINO DE DEUS SOB UM OLHAR FOUCAULTIANO
}

\author{
The "Fast of Daniel": the audiovisual detox the Universal Church of Kingdom of God under \\ the perspective of Michel Foucault
}

\author{
Marina Fazani Manduchi \\ Mestranda em História Social \\ Universidade Estadual de Londrina e \\ bolsista da Capes. \\ marinamanduchi@hotmail.com
}

RESUMO: O presente trabalho, inserido no campo da história cultural, tem por objetivo, à luz de Michel Foucault, analisar de que maneira as subjetividades dos fiéis da Igreja Universal do Reino de Deus são construídas. Diante da multiplicidade da Igreja Universal, optei por explorar uma de suas campanhas, denominada "Jejum de Daniel". A campanha, referindo-se ao Daniel bíblico, que jejuou por 21 dias se sacrificando em nome de Deus, também propõe aos fiéis da Igreja que jejuem por 21 dias. No entanto, o sacrifício proposto não é alimentício e sim, midiático, ou seja, a abstinência de qualquer tipo de mídia, um tipo de desintoxicação audiovisual, com o objetivo de ser batizado com o Espírito Santo. Os meios midiáticos da Igreja Universal dedicam-se ao Jejum, disponibilizando orientações e prescrições aos fiéis. Além das orientações, o que chama atenção são os resultados, amplamente divulgados por meio de testemunhos dos fiéis. São esses discursos, o institucional e do fiel, que pretendo abordar com base em conceitos do filósofo francês: discurso, poder e em especial, as técnicas de si, explorado nos seus últimos cursos no Collège de France.

Palavras-chave: História Cultural; Mídia; Igreja Universal do Reino de Deus; Michel Foucault.

ABSTRACT: This work is related to the field of Cultural History, and through the perspective of Michel Foucault, it aims to analyze how the subjectivities of the adherents of the Universal Church of the Kingdom of God are built. Given the multiplicity of activities of the Universal Church, I chose to explore one of his campaigns, called "The Fast of Daniel." As the campaign refers to the biblical character of Daniel, who fasted for 21 days sacrificing himself in the name of God, the Church also proposes to its believers the fasting for 21 days. However, the proposed object of sacrifice is not the consumption of food, but of the media, that is, the abstinence from any type of media, a kind of audiovisual detox, in order to be baptized with the Holy Spirit. The media resources of the Universal Church are dedicated to fasting, providing guidelines and prescriptions to the adherents. Besides the guidelines, which called our attention were the results widely disseminated through testimonies of the believers. I intend to approach these discourses, institutional and individual, based on the concepts developed by the French philosopher Foucault: discourse, power, and in particular the techniques of the self, explored in his last courses at the Collège de France.

Key-words: Cultural History; Media; Universal Church of Kingdom of God; Michel Foucault. 


\section{Introdução}

Diante das inovações e possibilidades abertas no campo historiográfico, em desenvolvimento desde a década de 1930, reconhecemos as importantes contribuições do movimento dos Annales, assim como a ascensão dos estudos culturais. Tais inovações abriram um leque de possibilidades ao historiador, que, em diálogo com outras disciplinas, disponibilizaram inúmeros métodos, objetos, teorias, temas, tipos de fontes, etc.; deixando pra trás uma historiografia excludente, relegada ao século XIX.

Dessa maneira, os caminhos abertos pela história cultural possibilitaram ao historiador deleitar-se sobre inúmeros e diversos objetos de pesquisa; e de forma ampla e diversificada, também permitiram que escolhêssemos as proposições teóricas e metodológicas que constituem o alicerce de qualquer pesquisa. Há anos, tal corrente historiográfica tornou-se a queridinha nos departamentos de história, desbancando as correntes anteriores, como a criticada historiografia metódica, a história social marxista em voga nos anos 60 e as primeiras gerações do movimento dos Annales focadas em uma história socioeconômica.

$\mathrm{Na}$ consolidação da história cultural e posterior surgimento da Nova História Cultural, um nome se destacou: Michel Foucault. O filósofo francês teve grande repercussão, positiva e negativa, no campo historiográfico; apesar das críticas, temos de reconhecer que suas contribuições foram valiosas para repensarmos o modo como fazíamos história. Ao criticar a história tradicional com sua narrativa contínua, linear, acontecimental, coesa, teleológica e evolutiva, Foucault concorda com as inovações da história nova, que adota uma postura, não mais preocupada em reconstituir o passado tal qual aconteceu, revelando uma sagrada "verdade", mas, empenhada em desconstruir esse passado enquanto discurso.

A história, na visão de Foucault, não seria mais uma narrativa cronológica, linear e progressiva dos acontecimentos do passado, mas uma narrativa preocupada em revelar as rupturas. De forma arqueo-genealógica, Foucault procurava identificar nas formações discursivas, o modo como cada época possibilitou o surgimento de alguns saberes e para isso, seria preciso escavar verticalmente as diversas camadas descontínuas dos discursos, para então, desnudar práticas discursivas que constituíram historicamente sujeitos e objetos. Assim, a abordagem foucaultiana destaca os efeitos dos "acidentes" 
ao invés do progresso das ideias e das origens. Enfatizando as descontinuidades e as rupturas, Foucault afirmava, "[...] Tudo aquilo que pode haver de irregular, de casual, de imprevisível, num processo histórico me interessa consideravelmente." (POL-DROIT, 2006, p. 98) O filósofo também afirmava fazer um uso instrumental da história e que, a partir de questões que ele se deparava na atualidade, começava a enxergar a possibilidade de uma história.

Nesse cenário de transformações, o campo historiográfico redescobriu, com influências da sociologia e da antropologia, a religião. A partir disso, o foco, em um enquadramento cultural, incidiu sobre uma história das práticas religiosas, ou seja, o historiador cultural não visa uma história da religião total, englobando todos os aspectos, construindo uma história evolutiva desde os primórdios, recheados de fatos e nomes importantes; esse tipo de narrativa historiográfica que busca as origens, que se constitui linearmente, de forma progressiva e coesa, somente satisfaz o desejo de historiadores que pararam no tempo.

A partir dessas mutações historiográficas, o objeto pesquisado neste artigo tornou-se passível de pesquisa, legitimado e inserido no campo da história cultural. Interessante destacar que o surgimento do objeto de pesquisa coincide com um período de grandes transformações na historiografia e com o sucesso das obras foucaultianas, pois, foi no final da década de 1970 que a Igreja Universal do Reino de Deus surge no subúrbio da cidade do Rio de Janeiro, mesma época em que a Nova História Cultural começava a se consolidar em centros acadêmicos europeus e norte americanos ${ }^{1}$. Segundo o historiador Peter Burke (2005, p. 07) "A história cultural, outrora uma Cinderela entre as disciplinas, desprezada por suas irmãs mais bem-sucedidas, foi redescoberta nos anos $1970[\ldots]$ [... Assim, cabe ao historiador cultural averiguar o papel que o fenômeno religioso desempenha em relação às práticas e o comportamento dos fiéis.

\footnotetext{
${ }^{1}$ No artigo "História cultural e historiografia brasileira", o historiador Ronaldo Vainfas apresenta uma visão panorâmica da abordagem cultural na historiografia brasileira, discorrendo sobre o impacto da história das mentalidades, da história cultural e da micro-história no universo acadêmico brasileiro. Segundo Vainfas, tais correntes historiográficas, já consolidadas na Europa e Estados Unidos na década de 1970, chegaram somente alguns anos depois ao Brasil. Tal atraso gerou certa confusão entre os historiadores, que trataram história das mentalidades e história cultural como sinônimos, e que confundiram história das mentalidades, história cultural e micro-história, devido ao uso comum de "novos temas". Dessa forma, Vainfas (2009, p. 233) afirma que, "O atraso de 10 ou 15 anos que marcou a difusão dessas correntes no Brasil foi, em grande parte, responsável por tais confusões, pois todas essas inovações da historiografia, principalmente europeia, chegaram juntas ou, pelo menos, se difundiram juntas nos anos 1980."
} 
Neste artigo optamos por enxergar a Igreja Universal sob a luz do filósofo Michel Foucault. Uma das muitas formas de enxergamos a Universal através das lentes foucaultianas pode ser feita pelo estudo de campanhas realizadas pela instituição. A partir disso, explicitaremos as ferramentas foucaultianas: discurso, poder, e principalmente, as práticas do cuidado de si, que sustentaram o estudo da campanha denominada, "Jejum de Daniel". Nesse caso, selecionamos os últimos quatro anos da $\mathrm{IURD}^{2}$, para que possamos compreender o papel da campanha, lançada pela Igreja em 2011, analisando as práticas e o comportamento dos fiéis perante tais orientações.

Brevemente, podemos descrever o "Jejum de Daniel" como uma campanha nova (lançada em 2011), que, fundamentada no Daniel bíblico, propõe aos fiéis um jejum de 21 dias. Diferentemente do jejum bíblico, em que há uma abstinência de alimentos desejáveis (manjares, vinho e carne), o que se recomenda é uma abstinência midiática, uma "desintoxicação audiovisual”, ou seja, 21 dias sem contato com nenhum tipo de mídia (televisão, internet, rádio, revistas, jornais, filmes, músicas, etc.) além de nenhum tipo de lazer (teatro, cinema, passeios, etc.). Porém, o Jejum permite que os fiéis entrem em contato com as mídias produzidas pela própria Igreja Universal, assim, no período da campanha, os veículos midiáticos iurdianos preparam uma programação dedicada ao Jejum, com programas televisivos, radiofônicos, com matérias no jornal Folha Universal e no portal eletrônico, Arca Universal ${ }^{3}$. Tomando como principal fonte as matérias e testemunhos veiculados no portal e nos blogs dos bispos, procuraremos mostrar de que maneira a campanha caracteriza-se como uma estratégia de poder e produtora de subjetividade. $^{4}$

\section{A ascensão da História Cultural e as ferramentas de Michel Foucault}

\footnotetext{
2 Abreviação de Igreja Universal do Reino de Deus.

${ }^{3}$ O portal Arca Universal, principal portal evangélico da América Latina, foi substituído recentemente pelo portal Universal.org (www.universal.org), que foi ao ar no dia 02 de dezembro de 2013, com várias novidades, entre elas, o "Pastor online - 24 horas", onde o fiel pode entrar em um chat (ao entrar no chat o fiel insere seus dados, se identifica, dizendo se já frequenta, nunca frequentou, ou se está afastado e, seleciona o tipo de problema que está passando: problemas espirituais, de saúde, familiar, financeiro, sentimental e outros) e conversar com os pastores.

${ }^{4}$ Ressaltamos que as reflexões inseridas neste artigo decorrem de pesquisas, em desenvolvimento desde 2012, que analisam o uso dos meios de comunicação da Igreja Universal do Reino de Deus, focadas na campanha "Jejum de Daniel". Iniciada durante a Especialização em Religiões e religiosidades concluída em 2012 na Universidade Estadual de Londrina, a pesquisa, financiada pela CAPES, se estende ao mestrado, no qual continuo aprofundando o tema, devido, especialmente, a grande quantidade de fontes.
} 
Para chegarmos até a emergência dos estudos culturais no campo da história, precisamos retornar e brevemente compreender qual o caminho percorrido. No início do século $\mathrm{XX}$, movidos por uma recusa à história biográfica, política e événementielle, o movimento dos Annales reuniu diversos historiadores dispostos a quebrar a redoma de vidro que isolava a história das demais ciências humanas, e assim "revolucionar" o campo historiográfico.

O intercâmbio com as ciências sociais, em especial com a sociologia e antropologia, promoveu inúmeras inovações no campo historiográfico, dentre elas podemos destacar: a mudança na concepção de tempo histórico (inspirado pelo conceito de estrutura das ciências sociais), o uso do termo "cultura" em um sentido antropológico, a crítica ao homem cartesiano, racional, consciente e produtor de conhecimento, (a partir disso, o homem não é mais considerado unicamente sujeito da história, mas também objeto), a proposição de uma história-problema, a renúncia à ideia de "naturalidade" (por exemplo, considerar o conceito "homem" como natural), a recusa em enxergar inocentemente o documento como revelador de um passado "tal qual aconteceu", como portador de uma "verdade histórica" (mas sim como texto, discurso produzido em outra época), o alargamento das fontes, uma ampliação dos temas de pesquisa, etc.

Diante dessas inovações, entendemos que, onde houver qualquer vestígio de existência humana torna-se possível a prática da pesquisa histórica; como diria o fundador dos Annales, Marc Bloch (2001, p. 54), “[...] o bom historiador se parece com o ogro da lenda. Onde fareja carne humana, sabe que ali está a sua caça”. Assim, observamos um alargamento de fontes que se libertaram das folhas de papel e que se estenderam a todo tipo de linguagem produzida pelo ser humano. Como afirmou o historiador Jacques Le Goff (2001, p. 50), “A explosão documental é, em parte, resultado do desejo do historiador de se interessar, de agora em diante, por todos os homens." Assim, interessados em todos os homens, derrubamos as muralhas e deixamos a história livremente se misturar às ciências humanas, dessa maneira, ampliamos nossas possibilidades, buscando novos objetos de pesquisa, novas fontes, novos métodos e novos conceitos. A história política, biográfica e heróica, foi sendo lentamente suplantada por uma história preocupada com o homem enquanto indivíduo que produz, habita, relaciona-se, pensa, ama, exercita-se, reza, vota, lê, enfim, que representa as suas 
necessidades e sentidos.

A partir do caminho aberto pelos Annales e diante de uma virada cultural nas ciências humanas entre as décadas de 1960 e 1990, o campo historiográfico aproximouse da antropologia. O interesse pela cultura popular fez com que os historiadores se aproximassem do trabalho do antropólogo. Utilizando as palavras de Le Goff, a antropologia tornou-se uma "interlocutora privilegiada". A partir desse intercâmbio, cunhou-se a expressão "história antropológica", em que José Carlos Reis afirmou,

Essa história antropológica acentuou a desaceleração do tempo realizada por Braudel. Os gestos cotidianos, costumes, são abordados na perspectiva da "longa duração". A história cultural ganhou o lugar da história econômico-social. [...] Essa nova etno-história é mais descritiva, menos quantitativa, embora não exclua a quantificação. A "interpretação" do historiador retoma um espaço mais amplo. [...] A dimensão cultural se tornou mais importante. (REIS, 2000, p. 113)

Dessa forma, em relação a temas e objetos “[...] a preocupação com ritos e festas, mitos e crenças, sociabilidades e atitudes mentais, [...] pode ser considerado como um indício da aproximação realizada entre História e Antropologia." (PESAVENTO, 2005, p. 112). De acordo com o historiador Eduardo Albuquerque, o movimento dos Annales e a História Cultural promoveram significativas inovações para os estudos do fenômeno religioso, uma delas,

[...] foi refazer as dimensões do objeto em cada pesquisa sobre a religião, por considerá-la constituída por múltiplas facetas construídas social e historicamente. As categorias de classificação da religião foram repensadas e se enfatizou sua ligação com temas como o amor, a mulher, a criança, a família, a morte etc. Frente aos enfoques tradicionais, a religião deixou de estar isolada dos outros campos de saber e perdeu nitidez, mas ganhou em complexidade, porque novas relações históricas vieram à tona. (ALBUQUERQUE, 2007, p. 15)

A cultura, em especial a brasileira, como campo do historiador, não pode ser desvinculada do aspecto religioso. A pesquisa alemã, Religion Monitor: An International Comparison of Religious Belief, produzida pela Bertelsmann Fundation, 
divulgada em $2007^{5}$, apontou o Brasil como o $2^{\circ}$ país mais religioso do mundo, ficando atrás somente da Guatemala. A pesquisa afirmou que $96 \%$ dos brasileiros se declararam religiosos e que o Brasil estaria em terceiro lugar no quesito fiéis praticantes. Já em 2013, a mesma pesquisa afirmou que, "The largest numbers of people claiming to be "very", "fairly", or “moderately" religious are found in Turkey (82\%), Brazil (74\%), India (70\%), and the USA (67\%)." "6 Ou seja, o Brasil permanece em segundo lugar no quesito religiosidade.

Dessa forma, a história das religiões e das religiosidades, assim como o estudo das práticas religiosas tornou-se um tema válido e legítimo a partir da ascensão dos estudos culturais. De acordo com a historiadora Karina Kosicki Bellotti,

O que devemos fazer é entender como diferentes crenças e práticas fazem sentido para as pessoas e os grupos que as adotam, em contextos históricos específicos. Assim, a religião, por essa definição, é concebida dentro da História Cultural como algo construído historicamente. Não pode ser vista como uma instância à parte da vida social (como concebia a "velha" História das idéias), ou subordinada a estruturas econômicas (segundo alguns historiadores e sociólogos marxistas). (BELLOTTI, 2004, p. 100)

Pelo viés cultural, o fenômeno religioso adquiriu espaço nas indagações de muitos historiadores, e acreditamos que tal indício não pode passar despercebido. No Brasil, atualmente há inúmeros historiadores que realizam pesquisas com base nos fenômenos religiosos, assim como congressos acadêmicos ${ }^{7}$ voltados especialmente para discussões do campo religioso.

Destarte,

\footnotetext{
5 A pesquisa, divulgada pela BBC, pode ser encontrada no link a seguir. Disponível em: $\langle$ http://www.bbc.co.uk/portuguese/reporterbbc/story/2007/12/071218_religiaocrescenti.shtml〉 Acesso em: 12 jan. 2014.

${ }^{6}$ Pesquisa Religion Monitor: An International Comparison of Religious Belief, produzida pela Bertelsmann

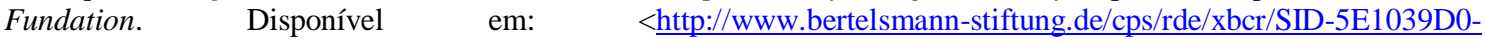
67810C8A/bst_engl/RelMo_Befunde-intVergleich_en.pdf > Acesso em: 15 jan. 2014.

${ }^{7}$ A título de exemplo, podemos citar o encontro anual realizado pela Associação Brasileira de História das Religiões (ABHR), assim como os encontros do Grupo de trabalho de História das religiões e das religiosidades promovido pela Associação Nacional de História (ANPUH) realizado bienalmente, entre diversos outros encontros, seminários e colóquios realizados por grupos e laboratórios de pesquisa em religião e religiosidades de todo país, como o Laboratório de Estudos sobre as religiões e religiosidades (LERR) da Universidade Estadual de Londrina e o Núcleo Paranaense de Pesquisa em Religião (NUPPER), núcleo de pesquisa interinstitucional coordenado por professores da Universidade Federal do Paraná.
} 
Domínios temáticos os mais diversos - como a História da Guerra, a História Urbana, a História da Religião, e tantos outros - apresentam-se muito habitualmente como campo de incidência para a História Cultural. Assim, por exemplo, a opção de historiadores pela História da Igreja ou pela História da Religião, desloca-se com a incidência da História Cultural para uma "História das Religiosidades", ou, mais propriamente falando, uma História das Práticas Religiosas. (BARROS, 2012, p. 58)

Seguindo a trilha aberta pelos Annales e baseando-se no sucesso dos estudos culturais na historiografia, a Nova História Cultural pode-se firmar como modalidade historiográfica. No final da década de 80, a expressão "Nova História Cultural" começou a ser empregada para designar novos trabalhos de historiadores influenciados por diversos campos: antropologia, teoria literária, linguística, filosofia, entre outros. Segundo Peter Burke (2005, p. 68), “A NHC (Nova História Cultural) é a forma dominante de história cultural - alguns até mesmo diriam a forma dominante de história - praticada hoje." Para Burke, quatro teóricos foram importantes para os praticantes da Nova História Cultural, entre eles: Mikhail Bakhtin, Norbert Elias, Michel Foucault e Pierre Bourdieu.

José D’Assunção Barros também chama atenção para os novos nomes da Nova História Cultural,

Outra corrente importante da História Cultural é aquela que tem atentado para os aspectos discursivos e simbólicos da vida sociocultural. Michel de Certeau e Pierre Bourdieu são aqui influências importantes; e o mesmo se pode dizer com respeito à contribuição da análise de discurso de Michel Foucault e Roger Chartier. Recolocar a noção de discurso no centro da História Cultural é considerar que a própria linguagem e as práticas discursivas que constituem a substância da vida social embasam uma noção mais ampla de Cultura. (BARROS, 2011, p. 41)

Nessa mais nova modalidade historiográfica, um filósofo se destaca e aterroriza alguns departamentos de história empoeirados: Michel Foucault. Fundamentado no pensamento e contribuições de Foucault para o campo historiográfico, optamos por utilizar suas ferramentas conceituais como alicerce para analisar a campanha o "Jejum de Daniel" promovida pela Igreja Universal do Reino de Deus. 
Ao abordar temas marginais como a loucura, os anormais, o poder, a prisão, a sexualidade, o cuidado de si, entre outros, a obra ${ }^{8}$ de Foucault deixou sua marca na Nova História Cultural, "revolucionando a história", segundo Paul Veyne. Contemporâneo das mudanças historiográficas, o filósofo preocupou-se em teorizar sobre a historiografia e o trabalho do historiador. Portanto, reconhecendo a importância de Foucault para a historiografia, nos questionamos: de que maneira podemos utilizar as ideias de Foucault? E o filósofo, em entrevistas concedidas a Roger Pol-Droit, respondeu essa questão com grande clareza.

Todos os meus livros, seja História da Loucura seja outro podem ser pequenas caixas de ferramentas. Se as pessoas querem mesmo abri-las, servirem-se de tal frase, tal ideia, tal análise como de uma chave de fenda, ou uma chave-inglesa, para produzir um curto-circuito, desqualificar, quebrar os sistemas de poder, inclusive, eventualmente, os próprios sistemas de que meus livros resultaram... pois bem, tanto melhor! (POL-DROIT, 2006, p. 52)

Destarte, com base nas próprias palavras de Foucault, podemos utilizar suas obras, suas ideias, seus conceitos, como se estivessem dispostos em uma caixa de ferramentas, onde possamos nos servir para construir o alicerce desse artigo. Assim, precisamos ter em mente que,

Para entrar no círculo de Foucault, não se pode reconhecer nada como dado. "Nada, no homem - nem mesmo o seu corpo - é suficientemente estável para servir de base para o reconhecimento de si mesmo ou a compreensão dos outros homens". A própria noção de "homem" é uma "invenção recente" da cultura européia a partir do século XVI. O Estado, o corpo, a sociedade, o sexo, a alma e a economia não são objetos estáveis, são discursos. (POL-DROIT, 2006, p. 47)

Na obra Como se escreve a história e Foucault revoluciona a história, o historiador Paul Veyne dedicou um texto ao filósofo, e dissertou sobre essa

\footnotetext{
${ }^{8}$ A obra de Foucault costuma ser dividida em três fases. A primeira de caráter arqueológico tem como principais obras a História da Loucura, As palavras e as coisas e A arqueologia do Saber; a segunda fase caracteriza-se por ser genealógica, com obras e cursos ministrados no Còllege de France sobre o sistema prisional e o poder, que datam da década de 1970; e na década de 1980, a terceira e última fase sobre a estética da existência, correspondendo aos volumes da História da Sexualidade e os últimos cursos ministrados: A hermenêutica do sujeito, $O$ governo de si e dos outros e A coragem da verdade.
} 
"revolução". Em especial, Veyne faz uma analogia que esclarece a noção de discurso proposta por Foucault,

A cada época, os contemporâneos estão, portanto, tão encerrados em discursos como em aquários falsamente transparentes, e ignoram que aquários são esses e até mesmo o fato de que há um. As falsas generalidades e os discursos variam ao longo do tempo; mas a cada época eles passam por verdadeiros. De modo que a verdade se reduz a um dizer verdadeiro, a falar de maneira conforme ao que se admite ser verdadeiro e que fará sorrir um século mais tarde. $A$ originalidade da busca foucaultiana está em trabalhar a verdade no tempo. (VEYNE, 1995, p. 25) (Grifo nosso)

Mais especificamente, para compreendermos a definição de discurso para Foucault, precisamos conhecer o livreto: A ordem do discurso. Este é a transcrição da aula inaugural que o filósofo pronunciou no Collège de France em 1970, quando passou a ocupar a cadeira "História dos sistemas de pensamento". Nessa aula, a respeito da noção de discurso, podemos claramente observar de que maneira Foucault pensa o discurso e seus procedimentos de ordenação, de controle e delimitação. Como o próprio título sugere, Foucault propõe uma ordem que orienta toda a produção do discurso. Assim, propõe uma análise do discurso com diversos procedimentos, que controlam, limitam, legitimam e instauram uma ordem para a formação dos discursos.

Essa análise do discurso apresenta três pontos importantes que se relacionam: a vontade de verdade, a vontade de saber e a noção de poder. Pensando nessa relação, aquele que tem legitimidade para proferir um discurso e gerar uma verdade, também gera um poder sobre os outros discursos, assim, o saber instrumentaliza o poder. Assim, aprendemos com essa noção de discurso, que nos encontramos encerrados em discursos que nos parecem tão naturais, como vidros falsamente transparentes de um aquário, e que precisamos desnudar tais discursos, enxergar mais de perto, escavar mais a fundo, e considerar que tudo à nossa volta foi construído historicamente através dos discursos.

Ao entender o que Foucault concebe por discurso, é possível compreender sua relação com o poder. Na segunda fase de sua obra, Foucault volta-se para a questão do poder, e este não pode ser entendido como algo que alguém detém ou que está representado por uma instituição. Podemos pensar o poder seguindo as palavras de Roger Pol-Droit, 
Rompendo com os postulados habituais, Foucault mostra que o poder é exercido, mais do que detido (só o detemos, exercendoo). É criativo, mais do que repressivo: ele incita, suscita, tanto quanto proíbe. Ele é, enfim, co-extensivo ao social: o poder não está localizado num lugar. Presente em toda relação de forças, passa tanto pelos dominados quanto pelos dominantes. Irredutíveis um ao outro, saber e poder são indissoluvelmente ligados. O jogo de forças do poder - aleatório, turbulento, flexível - engendra as mutações na distribuição do dizível e do visível, cuja articulação ele também regula. O poder é como um de-fora, sem forma estável, uma zona de tempestades, que só uma "microfísica" permite apreender. (POL-DROIT, 2006, pp. 30-31)

Dessa maneira, precisamos entender que, o poder não está inserido, detido, localizado, delimitado, ele existe como uma fina rede de micropoderes que perpassa toda a vida social. Cabe aos historiadores, ao enxergar essa rede microfísica do poder, observar sua função e identificar como o poder está atrelado à produção de verdade. Portanto, saber e poder operam na história de forma geradora. Por fim, são esses mecanismos de poder que buscamos, através do discurso, identificar e trazer à tona, mostrando de que maneira a campanha "Jejum de Daniel" pode ser considerada um mecanismo de poder.

A terceira ferramenta utilizada pertence à última fase de Foucault. Primeiramente, o filósofo nos dá indícios de investigar, ao longo de suas obras, de que maneira a subjetividade é construída historicamente, dessa forma, o sujeito passa a ser o "objeto" de sua investigação. Dessa forma, Foucault busca analisar a constituição do modo de ser do sujeito, ele não faz uma teoria do sujeito, não define o que é o sujeito, e sim, analisa como o sujeito se constrói, a forma de constituir o sujeito, ou seja, os modos de subjetivação e de que forma esses modos foram mudando ao longo da história.

Foucault ao criticar a concepção moderna de sujeito, que se apresenta como ser racional, consciente, como aquele que tem domínio sobre o objeto, que detém a verdade sobre o objeto; abre um novo caminho, para além da filosofia do sujeito, propondo uma genealogia do sujeito, em que, toma o sujeito como "objeto" de investigação, em detrimento da ideia de sujeito como fundamento do conhecimento. Dessa forma, o filósofo concebe a subjetividade como algo socialmente construído mediante forças 
internas (ações que o sujeito empreende sobre si mesmo) e externas (ações coercitivas). O sujeito foucaultiano está submerso pelo discurso, assim, não há dissociação entre sujeito e discurso. Para esclarecer essa noção de sujeito, citamos Paul Veyne,

[...] Pois, longe de ser soberano, o sujeito livre é constituído, processo que Foucault batizou como subjetivação: o sujeito não é "natural", ele é modelado a cada época pelo dispositivo e pelos discursos do momento, pelas reações de sua liberalidade individual por suas eventuais estetizações, [...] Assim, como sem um discurso, não haveria para nós objeto conhecido, não existiria sujeito humano sem uma subjetivação. Engendrado pelo dispositivo de sua época, o sujeito não é soberano, mas filho de seu tempo; não é possível tornar-se qualquer sujeito em qualquer época. (VEYNE, 2011, pp. 178-179)

Portanto, Foucault procurava mostrar como o sujeito era constituído, mediado pelo discurso, através de práticas, que eram estratégias de poder e jogos de verdade. $\mathrm{O}$ filósofo percebeu que, para além das forças externas coercitivas que agem sobre o sujeito, existia algo interno, uma força que fazia com que o sujeito agisse sobre si mesmo. Assim, podemos supor que Foucault corrigiu a unilateralidade do seu pensamento, voltando-se agora para as forças internas, mas sem descartar as externas. Essas forças internas, Foucault as nomeou de "técnicas de si", que são ações que o sujeito empreende sobre si mesmo com vistas de se transformar em algo diferente do que é. Como o próprio Foucault afirmou,

Se quisermos analisar a genealogia do sujeito na civilização ocidental, é preciso considerar não apenas as técnicas de dominação, mas também as técnicas de si. Devemos mostrar a interação que se produz entre os dois tipos de técnicas. Talvez eu tenha insistido demais, quando estudava os hospícios, as prisões etc., nas técnicas de dominação. [...] Tendo estudado o campo do poder tomando como ponto de partida as técnicas de dominação, gostaria de estudar, durante os próximos anos, as relações de poder partindo das técnicas de si. (FOUCAULT, 2004, p. 95) (Grifo nosso)

Nesse ponto, o aparato teórico-metodológico apresentado acima, permite refletir sobre como a subjetividade é construída, como o sujeito age sobre si mesmo através de sua pertença religiosa. A partir da análise do "Jejum de Daniel”, podemos nos indagar sobre como um fiel da IURD age sobre si mesmo? E como age sobre si mesmo de acordo com as orientações da Igreja? De certa forma, este artigo visa analisar e 
identificar através dos discursos, como a IURD prescreve um conjunto de técnicas de dominação, e como cada sujeito, o fiel, utiliza essas técnicas de forma diferente, agindo sobre si. Portanto, procuramos compreender como o sujeito iurdiano se constitui através de poderes e de técnicas de si. Por fim, acreditamos que o problema central consiste em, analisar de que forma as prescrições que orientam os fiéis da IURD durante o "Jejum de Daniel", também chamado de "desintoxicação audiovisual”, podem ser caracterizadas como produtoras de saberes, estratégias de poder e práticas ou técnicas do cuidado de si.

\section{Neopentecostalismo brasileiro e a Igreja Universal do Reino de Deus}

Para elencarmos os principais aspectos da IURD, precisamos inseri-la em um campo mais amplo. O pentecostalismo, desde o momento em que desembarcou no Brasil em 1910, não parou de crescer. O movimento pentecostal em solo brasileiro não se apresentou de forma homogênea e não expandiu suas vertentes de forma igualitária. Para compreender o impacto pentecostal, que crescia desordenadamente, alguns pesquisadores do fenômeno religioso acabaram por segmentar o movimento.

Um dos pesquisadores referência no assunto, o sociólogo Paul Freston, ressalta a importância de estudar as igrejas pentecostais em seu nível macro e destaca que elas estão em constante transformação, assim, "É hora de a sociologia da religião estudar as grandes igrejas pentecostais enquanto instituições em evolução dinâmica. Estas não são organizações estáticas que incham numericamente; estão em constante adaptação. [...]" (FRESTON, 1993, p. 64). Em constante adaptação, o pentecostalismo apresenta o lema "transformar para se adaptar", que pode ser visto em algumas igrejas pentecostais, e pode explicar o porquê de algumas igrejas pentecostais pioneiras perderem espaço e fiéis para as pentecostais da terceira onda, criadas no mundo moderno, portanto, mais sintonizadas com ele. Para observar os pentecostais em nível macro, Freston propõe uma divisão do pentecostalismo, dividindo-o em três ondas.

A primeira onda é a década de 1910, com a chegada da Congregação Cristã (1910) e da Assembléia de Deus (1911). Estas duas igrejas têm o campo para si durante 40 anos, pois suas rivais são inexpressivas. A Congregação, após grande êxito inicial, permanece mais acanhada, mas a $\mathrm{AD}$ se expande geograficamente como a igreja protestante nacional por excelência [...]. A segunda onda pentecostal é dos anos 50 e início de 60, na qual o campo pentecostal se fragmenta, a 
relação com a sociedade se dinamiza e três grandes grupos (em meio a dezenas de menores) surgem: a Quadrangular (1951), Brasil para Cristo (1955) e Deus é Amor (1962). O contexto dessa pulverização é paulista. A terceira onda começa no final dos anos 70 e ganha força nos anos 80. Suas principais representantes são a Igreja Universal do Reino de Deus (1977) e a Igreja Internacional da Graça de Deus (1980). Novamente, essas igrejas trazem uma atualização inovadora da inserção social e do leque de possibilidades teológicas, litúrgicas, éticas e estéticas do pentecostalismo. O contexto é fundamentalmente carioca. (FRESTON, 1993, p. 66)

Outra segmentação do campo pentecostal brasileiro que podemos destacar foi apresentada pelo sociólogo Ricardo Mariano, que propôs uma terminologia à terceira onda: "neopentecostalismo" 9 . O termo consolidou-se para expressar essa nova forma de religiosidade, e passou a ser rapidamente associado à Igreja Universal. Dirigindo o foco especificamente para a IURD, destacaremos algumas de suas principais características e episódios que marcaram seus 37 anos de existência.

Concordamos com Mariano, com a ideia de que a IURD caracteriza um "neo", um novo tipo de pentecostalismo. Mas, afinal, quais são as características que possibilitaram a criação de uma nova onda, de um novo pentecostalismo, de uma nova modalidade religiosa? Compreendemos que a IURD, por estar inserida no campo pentecostal, apresenta continuidades em relação às demais denominações pentecostais, porém, o nosso foco recai sobre as diferenças que caracterizaram o surgimento dessa nova onda. Entre as diversas características, podemos citar: a ênfase na Teologia da Prosperidade, o enfoque na existência de uma guerra santa: num embate ferrenho com o diabo e com as religiões católica e espiritualistas (afro-brasileiras e espiritismo kardecista), amplo uso dos meios midiáticos, significativa participação no plano político partidário, liberalização dos "usos e costumes", crença em objetos simbólicos e organização empresarial.

Mais detalhadamente, a Teologia da Prosperidade se encontra enraizada na formação das igrejas neopentecostais. Atualmente, compreendemos o porquê da Teologia fazer tanto sucesso, como o próprio nome diz, o foco é a prosperidade do fiel,

\footnotetext{
${ }^{9}$ De acordo com a divisão proposta por Ricardo Mariano, há três vertentes pentecostais: o pentecostalismo clássico, o deuteropentecostalismo e o neopentecostalismo, esta última se inicia na segunda metade dos anos 70. Além de algumas características válidas para as outras vertentes, o neopentecostalismo se distingue pela a intensa guerra espiritual contra o diabo, a importância dada à Teologia da Prosperidade e a liberalização dos usos e costumes.
} 
onde a moeda de troca entre Deus e o ser humano é o dinheiro. Podemos até elaborar uma equação da prosperidade: [ser dizimista ${ }^{10}$ fiel + ofertar (principalmente, aquilo que lhe fará falta + ter fé nos planos de Deus $=$ obter vida próspera e feliz + boa saúde + libertação dos demônios]. É com base nessa equação da prosperidade, que grande parte das denominações neopentecostais atrai milhares de fiéis, em que a comprovação do sucesso da equação é feita através dos testemunhos. Importante destacar que, o elemento fundamental da equação é a fé, assim, a responsabilidade sobre o alcance das bênçãos recai sobre o fiel, sendo a falta de fé que o faz sucumbir. De acordo com Mariano,

\begin{abstract}
Estes pregadores afirmam que só não é próspero financeiramente, saudável e feliz nessa vida quem carece de fé, não cumpre o que diz a Bíblia a respeito das promessas divinas e está envolvido, direta ou indiretamente, com o Diabo. A posse, a aquisição e exibição de bens, a saúde em boas condições e a vida sem maiores problemas ou aflições são apresentados como provas da espiritualidade do fiel. (MARIANO, 1999, p. 157)
\end{abstract}

Para ser próspero, além de ter fé e ofertar, o fiel precisa estar atento à outra característica iurdiana: a crença na existência e poder do diabo e seus demônios. Não adianta ter fé, pagar o dízimo em dia, fazer ofertas, se há demônios atormentando a vida, é preciso, primeiro ser exorcizado para tirar todo o mal, para então seguir o caminho da prosperidade. A guerra declarada contra o mal está presente em todos os templos e há cultos semanais dedicados a este problema. As "Sessões do Descarrego" tem como objetivo libertar as pessoas dos demônios que causam todos os tipos de males terrenos, somente a IURD com seus bispos e pastores, possuem legitimidade e poder para expulsar espíritos do mal e transformar a vida das pessoas. No site oficial da IURD há uma descrição e objetivo do culto,

Muitos chegam a essa reunião em uma total situação de decadência, mas, a partir do momento em que se voltam para avaliar como estão as próprias vidas, percebem que precisam obter forças para lutar contra tudo o que as deixa para baixo e infelizes devido aos mais diversos problemas. Assim, reconhecendo e lutando contras esses impedimentos, dão um grande passo rumo a uma completa mudança de vida.

\footnotetext{
${ }^{10}$ O dízimo diz respeito aos $10 \%$ do salário estipulado no holerite.
} 
Infelizmente, é cada vez mais alto o número de pessoas atormentadas por problemas de ordem espiritual. Alguns casos como visão de vultos, audição de vozes, doenças que os médicos não descobrem a causa, insônia, vícios e inveja, além de depressão e estresse, são males que tiram a paz das pessoas que procuram auxílio nessa área da vida. ${ }^{11}$

Assim, o fiel precisa reconhecer que há uma "força maior" impedindo sua felicidade e prosperidade. A partir do momento que ele reconhece e admite a existência dessa força maligna, a IURD entra em cena e adquire o poder e instrumentos necessários para combater esse mal. O antropólogo, Ronaldo de Almeida, no texto "Guerra de possessões”, apresenta alguns sintomas que são descritos pela IURD como sinais de possessão.

Para a Universal não existe meio-termo: o mundo está dividido entre pessoas "libertas" e "não-libertas", sendo que nestas há a constante atuação do diabo. Ele é o causador de todos os males e infortúnios da vida. Com a finalidade de diagnosticar as pessoas que devem ser submetidas ao exorcismo, a Igreja Universal elencou alguns sintomas mais frequentes que denunciam algum tipo de possessão demoníaca: nervosismo, dores de cabeça constantes, insônia, medo, desmaios ou ataques, desejo de suicídio, doenças cujas causas os médicos não descobrem, visões de vultos ou audição de vozes, vícios e depressão. (ALMEIDA, 2003, pp. 322-323)

Outro grande alicerce da IURD que dá suporte as características descritas acima, é o amplo uso dos meios midiáticos. A Igreja, como dissemos, soube aproveitar o momento de expansão dos meios midiáticos na década de 1980, e com ousadia passou a adquirir inúmeros meios de comunicação, como estações de rádio, emissoras de televisão, jornais, revistas, sites e blogs. Evoluindo juntamente com as tecnologias midiáticas, a Universal compreendeu o poder, o alcance e a influência da mídia, assim, soube enfatizar o uso da propaganda, marketing e publicidade. Como afirma o sociólogo, Leonildo Silveira Campos,

Até então, as organizações religiosas funcionavam atreladas à tradição, principal forma de transmitirem os valores e práticas religiosas. Após essas mudanças, as pessoas deixaram de orientar suas ações pelos programas embutidos nas instituições

11 PORTAL UNIVERSAL. Site oficial da Igreja Universal do Reino de Deus. Disponível em: <http://www.universal.org/reunioes/cura $>$. Acesso em: 20. abril. 2014. 
tradicionais e se tornaram dependentes da mídia, como fonte de modelos para regular seus comportamentos. Por isso, é impossível visualizarmos o drama social, sem uma análise do papel desempenhado pela propaganda e publicidade na montagem de um sistema religioso orientado pelo marketing. (CAMPOS, 1997, p. 239)

O uso dos meios midiáticos pelos pentecostais sempre foi motivo de polêmica e discórdia, algumas denominações pioneiras proibiam os fiéis de assistirem televisão, outras não utilizavam nenhum tipo de meio midiático para se expandir, enfim, os pentecostais pioneiros não desfrutavam dessas ferramentas do mundo moderno. A postura em relação à mídia se transformou devido ao investimento dos neopentecostais, que a utilizaram como elemento principal no processo expansionista. Tal inserção midiática se iniciou de forma acanhada, os neopentecostais começaram comprando espaços em rádios, ocupando horários durante a madrugada em emissoras de televisão; em seguida, com a expansão e maior arrecadação financeira, começaram a ocupar horários de maior visibilidade e até adquirir suas próprias emissoras.

Para Campos, intitulando-se como uma "Igreja de resultados", a Universal tornou-se um ótimo exemplo de organização religiosa que se expandiu e se mostrou atenta às necessidades modernas, devido ao uso de meios midiáticos e às estratégias de marketing. Para vender seu "produto" a IURD se compara com as outras igrejas, mostrando, de forma concorrencial, que o seu "produto" tem maior eficácia.

[...] para tornar o seu "produto" desejável, a IURD explora e provoca o descontentamento das pessoas para com as suas opções religiosas anteriores, mostrando a precariedade dos resultados até agora conseguidos nas agências concorrentes. Realmente, do ponto de vista "mercadológico", a Igreja Universal tem bons "produtos". O seu sucesso se deve também ao emprego dos canais de divulgação e de mecanismos de distribuição ágeis, pois permitem a chegada do produto ao consumidor certo, no momento exato, e na proporção desejada. (CAMPOS, 1997, p. 229)

Em suma, criada em um contexto muito diferente daquele das primeiras igrejas pentecostais, a IURD soube se adaptar melhor às necessidades de uma sociedade urbana e midiatizada. Adotando o lema "adaptar-se para crescer", a Igreja soube acompanhar as inúmeras mudanças da sociedade, especialmente, em relação aos meios midiáticos, 
investindo nesse campo, desde a explosão midiática da década de 80 até a revolução tecnológica contemporânea. Portanto, de acordo com diversos pesquisadores, a IURD caracterizou um "novo" pentecostalismo, com posturas e objetivos diferentes dos primeiros pentecostais. Compreendendo essas características, podemos contextualizar e explicitar o que é o "Jejum de Daniel".

\section{O "Jejum de Daniel"}

E Daniel disse: "Naqueles dias, eu, Daniel, estive triste, por três semanas completas. Manjar desejável não comi, nem carne nem vinho entraram na minha boca, nem me ungi com unguento, até que se cumpriram três semanas." (Dn 10. 2-3) ${ }^{12}$.

Essa passagem bíblica foi a inspiração para a criação da campanha "Jejum de Daniel", lançada pela IURD em 2011. Numa releitura contemporânea, a campanha mostra a forte característica que a Universal possui de se adaptar à atualidade. O Jejum iurdiano propõe aos fiéis que jejuem durante três semanas, assim como Daniel, no entanto, há uma imensa diferença no tipo de alimento que o fiel iurdiano deve se abster. Enquanto Daniel se privava de alimentos desejáveis (manjar, carne e vinho), os fiéis da IURD se abstêm de outro tipo de "alimento" que se tornou quase inerente à existência humana: os meios midiáticos. Assim, a IURD afirma que,

Quando o profeta Daniel sentiu-se amargurado pela situação na qual vivia junto com o povo, resolveu fazer um jejum. E por 21 dias ele ficou sem se alimentar de comida desejável, como carne, vinho e todas as iguarias do rei (Leia Daniel 9 e 10). O que significa que Daniel sacrificou em prol da resposta de Deus. Da mesma maneira, hoje, o maior sacrifício não é o jejum de alimentos, mas a total abstinência de informações, entretenimentos, músicas, televisão, enfim - diversões tais que nos rodeiam a todo instante. ${ }^{13}$

A partir da criação dessa campanha, compreendemos o papel importante que a mídia possui para Igreja. Mas, que papel é esse? Para entender esse papel, podemos brevemente eleger alguns episódios envolvendo a IURD que repercutiram na mídia.

\footnotetext{
${ }^{12}$ Para este texto foi utilizada a versão da Bíblia Almeida revista e corrigida. BÍBLIA. Português. Bíblia sagrada. Tradução por João Ferreira de Almeida. Rio de Janeiro: Juerp/IBB, 1998.

${ }^{13}$ ARCA UNIVERSAL. Site oficial da IURD. Disponível em:

< http://www.arcauniversal.com/institucional/jejum/marco2013/proposito>. Acesso em: 20 mar. 2013. (Grifo nosso)
} 
Alguns episódios, como os embates escancarados entre Record/IURD e Rede Globo já são velhas conhecidas. A IURD, desde sua criação, utilizou os meios midiáticos para se defender e atacar seus "inimigos" declarados, como a Rede Globo, as religiões afrobrasileiras, o catolicismo e seu clero, e até outras igrejas pentecostais. Assim, de tempos em tempos, a Igreja vira manchete de jornal, capa de revista e reportagem principal em programas televisivos de destaque.

Rapidamente podemos relembrar alguns dos episódios envolvendo a Universal e Edir Macedo: a prisão do Bispo Macedo, o episódio do "chute na santa", o vídeo em que Macedo ensina táticas mais eficazes para pedir dinheiro, malas recheadas de dinheiro apreendidas em aeroportos, relações duvidosas com eleição de prefeitos, e acusações e mais acusações de charlatanismo, estelionato, extorsão, formação de quadrilha, lavagem de dinheiro, entre outras denúncias. Edir Macedo, em sua primeira biografia autorizada, ao responder à repórter sobre sua prisão, declarou,

Edir Macedo - Você quer saber a verdade? Eles deram vários tiros no pé. A situação se reverteu a meu favor, para frustração de meus inimigos.

Repórter - Inimigos?

Edir Macedo - Eu tinha e tenho muitos inimigos.

Repórter - Quem era e quem são esses inimigos?

Edir Macedo - Quem eram? O clero católico, a Rede Globo e a gente poderosa usada por eles. Eu até entendo tantos ataques, realmente há motivos para isso. A Igreja Universal incomoda, a Record incomoda. Nós assustamos. Nosso crescimento assustou muita gente na época da minha prisão e continua assustando até hoje. (TAVOLARO, 2007, p. 27)

Dessa forma, a IURD, utilizando seus meios midiáticos orienta os fiéis a não darem crédito à mídia sobre o que é veiculado a respeito da IURD e de seu bispo. De acordo com o sociólogo Alexandre Fonseca,

Os fiéis da Universal vivem como que envolvidos em uma "redoma de mídia", que acaba por praticamente isolá-los. Eles possuem e participam de reuniões e correntes regulares nos templos, ouvem as emissoras de rádio da Igreja (AM ou FM), leem o jornal e assistem à emissora de tevê. Os livros lidos também são somente de seus líderes. Todo esse processo acaba por assegurar maior fidelidade dos membros, sendo formada 
uma identidade segundo os padrões da Igreja, que acaba sendo assimilada e seguida por uma porcentagem significativa de fiéis. (FONSECA, 2003, p. 279) (Grifo nosso)

Os motivos para isolarem os fiéis em uma "redoma de mídia" podem ser inúmeros, porém, suspeitamos que para além de um boicote à Rede Globo, essa redoma busca promover uma fidelização e a criação de uma identidade iurdiana. Assim como os evangélicos, de forma geral, que buscam a cada dia reafirmar sua identidade, a IURD, inserida no campo evangélico, também procura criar sua própria identidade. De acordo com Bellotti,

A identidade evangélica é, sim, tomada como algo que se constitui de forma relacional. $\mathrm{O}$ sentimento de pertença precisa ser renovado todo dia, a cada culto, a cada oração, a cada confronto com aquele que possui uma crença diferente. No Brasil, ser evangélico significa, muitas vezes, não ser católico, nem espírita e nem umbandista. Num país de cultura católica, ser evangélico requer um constante aprendizado, feito, dentre outras coisas, por meio de produtos de mídia. (BELLOTTI, 2004, p. 110)

Um dos possíveis motivos dessa "redoma midiática" pode ser o combate declarado contra as demais igrejas (especialmente, as neopentecostais) que utilizam amplamente os meios midiáticos. Tal suspeita pode ser observada em um episódio envolvendo a IURD, relacionada à campanha de um candidato à prefeitura de São Paulo. Macedo, em um culto para mais de seis mil fiéis em Santo Amaro, se defendeu das acusações e, segundo reportagem da Folha de São Paulo,

O carro-chefe do culto foi o avanço de outras igrejas evangélicas, como a Mundial do Poder de Deus (de Valdemiro Santiago) e Internacional da Graça de Deus (R. R. Soares, casado com uma irmã de Macedo), lideradas por dissidentes da Universal. "Não ouça nenhum pastor. Fixe-se aqui", instruiu bispo Macedo. Ele usou a metáfora de "misturar vinhos" para afirmar que o fiel deve escolher apenas uma denominação para seguir. ${ }^{14}$

E de acordo com a repórter, Macedo afirmou,

\footnotetext{
${ }^{14}$ Folha de São Paulo "Bispo Edir Macedo diz que nem conhece Celso Russomanno.", 28 setembro de 2012. Disponível em: $<$ http://www1.folha.uol.com.br/colunas/monicabergamo/1160470-bispo-edir-macedo-diz-que-nemconhece-celso-russomanno.shtml >. Acesso em: 29 setembro 2012.
} 
E eu pergunto: quem fica curado assim? [...] Andando feito piolho na cabeça dos outros. Você quer ser livre, defina sua vida, sua fé. Você se encaixou bem na igreja 'A', então fique nessa igreja. Não liguem a televisão tentando buscar outros canais que falem de Jesus. Todo mundo fala de Jesus, até o diabo fala de Jesus. ${ }^{15}$

Assim, a criação do Jejum não nos parece "despretensiosa", há indícios que apontam a campanha como uma estratégia de poder, pois, esta foi criada no momento em que a Igreja Mundial do Poder de Deus, do dissidente Valdomiro Santiago, ganhou destaque na televisão e começou arrebanhar mais fiéis; e no momento em que a IURD, segundo dados do Censo 2010 realizado pelo Instituto Brasileiro de Geografia e Estatística (IBGE), apresentou seu primeiro declínio, perdendo mais de 200 mil fiéis (passando de 2,102 milhões em 2000 para 1,873 milhões em 2010, apresentando uma diminuição de mais de 10,8\%), enquanto a pioneira Assembléia de Deus apresentou um crescimento importante ( passando de 8,4 milhões de fiéis em 2000, para, em 2010, atingir mais de 12,3 milhões de fiéis). Ou seja, a IURD sentindo os efeitos de seu declínio inédito e a possível rivalidade de outra denominação neopentecostal, precisou criar estratégias para conter a perda de fiéis e assegurar o rebanho.

Assim, a mídia adquire papel essencial nesse processo de manter o número de fiéis, e diante disso, a campanha propõe que é preciso abster-se da mídia laica e de lazer, para “crescer” espiritualmente, ao ser batizado pelo Espírito Santo. Bispo Macedo deixa essa ideia muito clara ao conclamar os fiéis a participarem do Jejum,

Muitos de nós desejamos mudar nossa maneira de pensar, agir, falar ou nos comportar, mas nem sempre conseguimos essa mudança tão esperada em nosso interior. Os motivos são inúmeros, e geralmente o excesso de informações e de preocupações que temos no nosso dia a dia pode influenciar e muito nisso. [...]contaminados com tanta informação desnecessária, excesso de lazer e entretenimento e coisas extras que nada acrescentam em nossas vidas, o máximo que conseguimos é nos distanciar cada vez mais do que realmente importa. ${ }^{16}$

15 Folha de São Paulo "Bispo Edir Macedo diz que nem conhece Celso Russomanno", 28 setembro de 2012. Disponível em:<http://www1.folha.uol.com.br/colunas/monicabergamo/1160470-bispo-edir-macedo-diz-que-nemconhece-celso-russomanno.shtml>. Acesso em: 29 setembro 2012.

${ }^{16}$ ARCA UNIVERSAL. Site oficial da IURD. Disponível em:

<http://www.arcauniversal.com/institucional/jejum/marco2013/proposito>. Acesso em: 20 mar. 2013. (Grifo nosso) 
Com base nessa citação de Macedo, podemos pensar nas técnicas de si propostas por Foucault, pois, a campanha associa a dificuldade do fiel em "transformar-se", em realizar uma mudança interior, ao excesso de informações, lazer e entretenimento desnecessários, que distanciariam o fiel "do que realmente importa". Nesse caso, o que "realmente importa" é o "alimento" espiritual, aproximar-se de Deus, dos ensinamentos de Cristo, da bíblia e de ser batizado com o Espírito Santo, e para tal, é preciso desintoxicar-se das atividades que afastam de Deus. É nesse ponto que a IURD cria a redoma de mídia, ao propor que o fiel realize uma desintoxicação audiovisual "secular", mas que se "alimente" dos meios midiáticos da Igreja.

Para criar essa redoma midiática, a IURD como um todo se volta para o Jejum, no portal eletrônico Universal.org há destaque para a campanha com links explicando o que é o propósito, como participar, além de disponibilizar mensagens e wallpapers. Dentre os diversos meios midiáticos explorados pela Igreja, percebemos que a internet tem sido utilizada como um dos principais veículos de comunicação, principalmente, pela facilidade do acesso (atualmente, acessamos a internet em qualquer lugar, pelo computador, celular, tablet, até pela televisão) e aproximação do público jovem. Devido à ênfase dada ao meio eletrônico e à quantidade documental, selecionamos as fontes deste artigo a partir do site oficial da IURD (no período da campanha, o site oficial ainda era o Portal Arca Universal (www.arcauniversal.com), que foi substituído em dezembro de 2013, pelo www.universal.org), assim como dos blogs do Bispo Macedo e de seu genro Renato Cardoso. Segundo o site oficial,

Desta vez, o Portal Arca Universal estará mergulhado no Jejum de Daniel. Aqui, você vai encontrar testemunhos de pessoas batizadas nas campanhas passadas, vai receber dicas de como se manter fiel e não quebrar o propósito, além de ter reflexões espirituais que certamente falarão diretamente com você. Ademais, você pode acessar o blog do bispo Edir Macedo, bem como os blogs de Cristiane Cardoso, bispo Renato Cardoso, bispo Júlio Freitas, Viviane Freitas, Fonte a Jorrar e Tânia Rubim, além da Rede Aleluia, dos programas da IURD TV e outros programas da IURD nas tevês Record e Gazeta. Você também pode acessar as páginas do Facebook do bispo Edir 
Macedo, IURD e Arca Universal, onde haverá atualização das mensagens que serão publicadas nos sites. ${ }^{17}$

A IURD, ao investir no meio eletrônico, produz um novo tipo de interação religiosa, possibilitando uma aproximação maior dos fiéis com a liderança da Igreja. Na dissertação de mestrado em Comunicação Social, Carlos Sanchotene apresenta a ideia de "religião 2.0", refletindo sobre esse novo tipo de interação internet - religião, ainda pouco pesquisada. Segundo ele,

A religião 2.0 é o ambiente interativo que move as práticas religiosas dos fiéis às práticas midiáticas. Todas essas ferramentas e recursos proporcionados pelas novas tecnologias são apropriados pelo campo religioso, fazendo emergir um outro conceito de religião. Ao se apropriar dessas ferramentas, a igreja promove a divulgação de suas marcas, de seus dispositivos midiáticos e também estabelece contato com seu público. (SANCHOTENE, 2011, p. 03)

Sobre o blog do Bispo Macedo, Sanchotene afirma,

Pelo fato de os fiéis terem a chance de manifestar suas opiniões, cria-se um sentimento de coparticipação que é possibilitado pelo blog, por meio dos comentários. Lógico que todo o conteúdo está condicionado a aos sistemas reguladores instituídos pela instância religiosa. [...] Pelo blog, há uma potencialização das trocas com seus fiéis e candidatos a fiéis, uma vez que prima por estabelecer contatos utilizando recursos distintos: linguagem diferenciada de textos, imagens, áudio e vídeo. Esses elementos dão ao fiel internauta a chance de expressarem a sua fé e manterem uma experiência religiosa de caráter multimídia. Por exemplo, a performance do bispo no blog, seja através dos textos ou de suas aparições em vídeos, gera vínculos e confiança na relação com o fiel internauta. Essa relação passa a ser marcada pela proximidade, pela convivialidade e pelo contato através da afetividade com o internauta. Então, além deles poderem comentar e contar suas histórias, o espaço interativo da internet também produz maior efeito verídico sobre a importância da IURD, para fazer com que suas vidas sejam transformadas, pois, no caso do blog, é um espaço de midiatização e conquistas. (SANCHOTENE, 2011, p. 02) 
Com base nas citações acima, percebemos a importância que os blogs vêm adquirindo na dinâmica da Igreja, assim, quando a IURD se dedica ao Jejum, os blogs dos bispos também se voltam para essa campanha. No blog do Bispo Edir Macedo, durante a campanha, são postadas mensagens com imagens e citações bíblicas, que se constituem em meditações para cada dia de Jejum.

Para este artigo, foram selecionadas, como discurso institucional, as orientações dadas pelo Bispo Renato Cardoso em seu blog. Em especial, as tarefas diárias propostas pelo bispo Renato, que postava diariamente cinco tarefas a serem realizadas pelos fiéis. As tarefas abrangem cinco aspectos diferentes: espiritual, saúde, relacional, financeiro e desenvolvimento. Compreendemos tais tarefas como prescrições de subjetividade, ou seja, técnicas de si, para que os fiéis ajam sobre si mesmos para tornarem-se diferentes do que são. Assim, o Jejum não é um "simples" abster-se, mas um "transformar-se" em algo diferente do que é.

A partir daqui elencaremos algumas tarefas e testemunhos, porém, é importante enfatizar que, ambos os discursos (tarefas e testemunhos), foram propositalmente selecionados. Começaremos observando as tarefas propostas para o primeiro dia de Jejum:

Dia 01 (13 de agosto de 2012). Tarefas: Espiritual - Falar com Deus ao começar o dia, pelo menos 5 minutos. Saúde - Fazer 30 minutos de atividade física. Ex: caminhar, alongar etc. Relacional - Contatar um familiar ou amigo com quem você não fala há muito tempo. Financeiro - Fazer uma lista atualizada de todas as suas dívidas.Desenvolvimento Perguntar a seu patrão ou profissional que lhe conhece e em quem confia: "Onde você acha que tenho que melhorar?".

Podemos perceber que as tarefas propostas procuram promover mudanças "efetivas" na vida do fiel, algumas de dentro pra fora, no caso da espiritual e da relacional, outras de fora para dentro, no caso da saúde, e a que costuma preocupar grande parte da população, a financeira. No segundo dia de tarefas, o bispo justifica o porquê de propor uma tarefa voltada para a saúde, "Na saúde, a maioria de nós hoje em dia come demais ou de menos. Temos hábitos alimentares muito ruins. Eis sua oportunidade de pensar um pouco sobre eles, e buscar o equilíbrio. Lembre-se, seu 
corpo é o templo do Espírito Santo. Cuidar bem dele também é um ato espiritual." ${ }^{18} \mathrm{O}$ cuidado com o corpo, como "templo do Espírito Santo", que tem de estar apto e saudável para recebê-lo, também pode ser visto como uma técnica de si, como a meditação, por exemplo, que visa o equilíbrio, o bem estar entre mente e corpo. No sexto dia, o bispo apresenta, o que também podemos considerar, uma técnica de si, na tarefa espiritual, "A sós com Deus: Passar de 10 a 30 min. sem distrações meditando na Palavra e conversando com Ele." 19

Nas tarefas do terceiro dia, podemos destacar a tarefa espiritual, financeira e desenvolvimento,

Dia 03 (15 de agosto de 2012) ${ }^{20}$ Tarefas: Espiritual - Ler Salmo $143: 10^{21}$ e orar pedindo a Deus que a vontade d'Ele seja feita em você; ir na igreja hoje. Financeiro - Escrever quanto você quer que sua renda mensal seja nos próximos 6-12 meses e colocar esse papel em sua carteira. Desenvolvimento Identificar um mau hábito* que você quer eliminar do seu comportamento.

Na tarefa espiritual, há uma orientação que chama atenção, o fato de orientar o fiel a "ir à igreja", ou seja, é preciso estar presente nos cultos, fazer parte da comunidade, compartilhar suas experiências com os demais. $\mathrm{Na}$ tarefa do desenvolvimento, podemos observar como o fiel é instigado a olhar para si, a identificar em si mesmo um mau hábito, ou seja, é preciso conhecer-te a ti mesmo para que possa haver mudança. E a tarefa no aspecto financeiro nos dá indícios da ênfase na Teologia da Prosperidade, onde esses desejos que aspiram a uma renda maior são estimulados. $\mathrm{O}$ bispo deixa ainda mais claro a ênfase na Teologia, na tarefa do quinto dia:

No financeiro, use o poder da sua imaginação (que é uma ramificação do poder da fé). Imagine com detalhes como você quer que sua vida profissional, seus negócios, suas conquistas, suas economias, e sua generosidade sejam até daqui a 12 meses. Tenha essa imagem fixa na sua mente. Viaje até lá em espírito.

\footnotetext{
18 Blog do Bispo Renato Cardoso. Disponível em: <http://www.bprenatocardoso.com/wpcontent/uploads/2012/08/Jejum-de-Daniel-02.pdf>. Acesso em: 14 ago. 2012.

19 Blog do Bispo Renato Cardoso. Disponível em:<http://www.bprenatocardoso.com/wpcontent/uploads/2012/08/Jejum-de-Daniel-06.pdf>. Acesso em: 18 ago. 2012.

20 Blog do Bispo Renato Cardoso. Disponível em:<http://www.bprenatocardoso.com/wpcontent/uploads/2012/08/Jejum-de-Daniel-03.pdf $>$. Acesso em: 15 ago. 2012.

${ }^{21}$ Salmos 143:10 - "Ensina-me a cumprir a tua vontade, pois tu és o meu Deus. Que o teu bom espírito me conduza por uma terra aplainada.".
} 
Veja tudo já concretizado pelos olhos da fé. E não se esqueça do que viu. ${ }^{22}$

Ainda na questão financeira, os fiéis são estimulados a tornarem-se empresários, investindo em seus próprios negócios, na tarefa do oitavo dia, ele expõe que,

No Financeiro, todos nós já tivemos boas ideias que morreram em nossa cabeça antes de nascerem. Usamos boas desculpas: falta de tempo, medo de não dar certo, não tenho ninguém que me apoie etc. As grandes empresas e os grandes produtos são frutos de uma ideia - e alguém que não teve medo nem preguiça de persegui-la. Portanto, essa é sua tarefa para hoje. ${ }^{23}$

E no décimo segundo dia, a tarefa reforça a equação da prosperidade e a importância do dízimo,

No Financeiro, considere esta regra de um grande homem de negócios: "Viva com $70 \%$ da sua renda; economize ou invista $20 \%$; mas dê os primeiros $10 \%$ para Deus." A título de exemplo, se você ganha $\mathrm{R} \$ 1.000$, se programe para viver com apenas $\mathrm{R} \$$ 700 , guarde ou invista $\$ 200$, mas sempre devolva o dízimo primeiro para Deus. A mesma fórmula pode ser aplicada na sua empresa, se você tem seu próprio negócio. ${ }^{24}$

Na tarefa do sétimo dia, fica claro o que Sanchotene apresenta no conceito de religião 2.0, em que os blogs tornam-se espaços de participação do fiel, gerando um sentimento de proximidade entre fiel e o bispo. Esse tipo de interação é bastante estimulado pelo bispo Renato durante o Jejum, assim, ele afirma que, "Completando as tarefas de hoje, você terá chegado a um terço do propósito. Como tem sido essa experiência para você? Divida seus comentários conosco, abaixo." "25 Ainda nas orientações para o sétimo dia de Jejum, o bispo Renato reafirma o que dissemos sobre a criação de uma redoma midiática ao propor aos fiéis uma tarefa extra,

\footnotetext{
22 Blog do Bispo Renato Cardoso. Disponível em: $<$ http://www.bprenatocardoso.com/wpcontent/uploads/2012/08/Jejum-de-Daniel-05.pdf >. Acesso em: 17 ago. 2012.

${ }^{23}$ Blog do Bispo Renato Cardoso. Disponível em: $<$ http://www.bprenatocardoso.com/wpcontent/uploads/2012/08/Jejum-de-Daniel-08.pdf >. Acesso em: 20 ago. 2012.

${ }^{24}$ Blog do Bispo Renato Cardoso. Disponível em: $<$ http://www.bprenatocardoso.com/wpcontent/uploads/2012/08/Jejum-de-Daniel-12.pdf >. Acesso em: 23 ago. 2012.

${ }^{25}$ Blog do Bispo Renato Cardoso. Disponível em: $<$ http://www.bprenatocardoso.com/wpcontent/uploads/2012/08/Jejum-de-Daniel-07.pdf >. Acesso em: 19 ago. 2012.
} 
Acrescento aqui também uma $6^{\mathrm{a}}$ tarefa que não está na tabela abaixo: assistir hoje a partir das $21 \mathrm{~h} 30$ (horário de Brasília) em ponto na TV Record o documentário especial: Raio X da Igreja Universal. Ame-a ou odeia-a, você saberá coisas nunca vistas ou faladas da IURD. ${ }^{26}$

No nono dia de tarefas, a orientação espiritual está fundamentada em uma das principais características da IURD: a guerra contra o mal. Assim, o bispo Renato afirma que,

O Senhor Jesus ensinou na Oração do Pai Nosso que deveríamos pedir ao Pai que nos livrasse de todo o mal. Se o mal não existisse, e não tivesse intenção de nos destruir, o Senhor não teria se importado de incluir esse ponto naquela oração-modelo. Portanto, começaremos o dia hoje repreendendo todo e qualquer mal que esteja ao nosso redor, atuando ou planejando alguma investida contra nossas vidas. ${ }^{27}$

No décimo primeiro dia de tarefas, o combate contra as forças malignas reaparece como tarefa espiritual, "Jesus nos ensinou a orar diariamente para que o Pai não nos deixasse cair em tentação. Muitas vezes nos esquecemos disso. Sua tarefa de hoje será perceber onde ou em quê tem sido tentado, e repreender o mal." 28

Ainda em relação ao Jejum, expomos algumas recomendações e comentários no último dia feitos pelo bispo Cardoso. Atentamos para o discurso motivador encontrado em vários dias do Jejum, a recomendação para que os fiéis continuem perseverantes nos propósitos realizáveis a longo prazo, para os benefícios que o Jejum proporcionou e a possibilidade de continuar melhorando. Assim, o bispo sugere quatro passos: que as pessoas acessem o seu blog diariamente, que guardem essas tarefas, e em especial, que deem um feedback para a Igreja, ou seja, que deem seu testemunho sobre a realização do Jejum (aqui podemos perceber o quanto esse retorno alicerça a campanha) e que "Nunca pare de melhorar. Quem não melhora, piora. Um de meus objetivos nesse blog é desafiá-las a se tornar uma pessoa melhor, em tudo, usando a sua inteligência

\footnotetext{
${ }^{26}$ Blog do Bispo Renato Cardoso. Disponível em: $<$ http://www.bprenatocardoso.com/wpcontent/uploads/2012/08/Jejum-de-Daniel-07.pdf >. Acesso em: 19 ago. 2012.

${ }^{27}$ Blog do Bispo Renato Cardoso. Disponível em: $<$ http://www.bprenatocardoso.com/wpcontent/uploads/2012/08/Jejum-de-Daniel-09.pdf >. Acesso em: 21 ago. 2012.

${ }^{28}$ Blog do Bispo Renato Cardoso. Disponível em: $<$ http://www.bprenatocardoso.com/wpcontent/uploads/2012/08/Jejum-de-Daniel-11.pdf >. Acesso em: 23 ago. 2012.
} 
espiritual", ou seja, empreendendo técnicas sobre si mesmo através de orientações da Igreja e utilizando a "inteligência espiritual", o fiel pode transformar-se em algo diferente do que era, ou seja, constituir-se enquanto sujeito.

Para compreendermos essa "produção" da subjetividade, podemos expor uma das principais ferramentas da IURD, o testemunho. Podemos explicitá-los para ilustrar essa "transformação" que o fiel relata depois de realizar o Jejum. Abaixo, os testemunhos publicados nos primeiros dias de Jejum, enquanto o bispo Macedo realizava uma oração pelo rádio.

J. S. ${ }^{29}$ - "Eu estava ouvindo a Palavra quando o senhor pediu para colocarmos a mão no rádio. Eu coloquei com toda minha Fé e no mesmo instante o Espírito Santo invadiu o meu ser com uma ALEGRIA e uma PAZ que não cabiam em mim, e na mesma hora eu falei em línguas. [...]"

L. - "Bispo, hoje tive a confirmação com o Espírito Santo, na rádio. O senhor disse para falar em línguas na hora, e eu falei. Eu estava afastado há 8 anos, voltei há um mês e estou avivado nesta campanha, pois cada vez mais sinto o PODER." 30

Podemos observar, em ambos testemunhos, as características descritas ao "receber" o Espírito Santo: uma sensação de felicidade, paz, leveza e falar em línguas. Os dois testemunhos abaixo relatam as transformações, antes e depois do Jejum.

R. B.- 26 anos, "Há muito tempo estava afastado de Deus. Era casado e fazia parte da Força Jovem, mas acabei saindo da IURD. Logo após, me separei e passei a viver de festas e bebidas. Era uma pessoa impulsiva, não pensava antes de fazer nada e era inconsequente nos meus atos. Eu também era muito nervoso, sem paciência, e me irritava facilmente. Há 3 meses cheguei ao Cenáculo do Espírito Santo e, 1 mês depois, começou o propósito do Jejum de Daniel. Essa foi a oportunidade de recomeçar. Entreguei-me de corpo, alma e espírito. Participei das orações realizadas através da Rede Aleluia. Vinha quase todos os dias ao Cenáculo. Após uma semana de jejum, eu fui selado com o Espírito Santo. Hoje, tudo está diferente. Deus me abriu os olhos. Agora sou uma pessoa

\footnotetext{
${ }^{29}$ Optamos por omitir o nome por extenso das pessoas que têm seu testemunho publicado no site Arca Universal, para evitar exposição da vida privada de forma desnecessária.

${ }^{30} A R C A$ UNIVERSAL. Disponível em:<www.arcauniversal.com/iurd/noticias/pessoas-relatam-batismo-nosprimeiros-dias.8242.html>. Acesso em: 23. fev. 2013.
} 
paciente, tolerante. Até os amigos de trabalho notam a diferença. Estou firme e mais próximo de Deus." 31

R. A. -23 anos, "Minha vida não tinha sentido. Estava tudo em ruínas, não tinha paz e vontade de viver. Quando ouvi falar dos 21 dias do 'Jejum de Daniel' vi a oportunidade de mudar. Abri mão de muitas coisas que gostava de fazer como, por exemplo, leitura de jornais e revistas e assistir tevê. Após a campanha, recebi o Espírito Santo. Hoje tenho paz. Minha vida mudou completamente. Tenho um relacionamento abençoado, uma vida próspera e confiança no que faço, porque Deus está à frente de tudo. Agora minha vida tem sentido. Hoje posso dizer: Ah, que dia!", afirma. ${ }^{32}$

Nos testemunhos, podemos perceber as transformações de dois homens jovens, que após realizarem o Jejum e serem batizados pelo Espírito Santo, tiveram suas vidas transformadas. Além do Jejum se apresentar como uma oportunidade de "recomeçar", as frases "Hoje tudo está diferente" e "Minha vida mudou completamente", entre dezenas de outros testemunhos selecionados, fica claro que o fiel, através dos discursos produzidos pela IURD (em forma de orações, orientações, normas, regras, recomendações etc.) empreende "técnicas sobre si" e a partir delas se transforma em outro diferente do que era.

Portanto, após cinco edições realizadas, o "Jejum de Daniel”, mesmo sendo uma campanha "jovem", pode ser considerado uma estratégia eficiente na produção de subjetividade. Apropriando-se de algumas ferramentas foucaultianas, percebemos, ao observar os discursos, que a IURD prescreve normas e de que maneira essas normas, atravessadas de poder, podem ser consideradas "técnicas de si", em que o fiel, ao empreender essas técnicas sobre si mesmo, acaba por se transformar em algo diferente do que era. Em alguns testemunhos, fica nítida essa característica "transformadora" da campanha. Por fim, podemos crer que o problema consiste em, analisar de que forma as prescrições que orientam os fiéis da IURD durante o Jejum podem ser caracterizadas como estratégias de poder e práticas ou técnicas do cuidado de si.

\footnotetext{
${ }^{31}$ ARCA UNIVERSAL. Disponível em: <www.arcauniversal.com/iurd/noticias/espirito-santo-e-derramado-sobremultidoes-7133.html>. Acesso em: 23 fev. 2013.

${ }^{32}$ ARCA UNIVERSAL. Disponível em:<www.arcauniversal.com/iurd/noticias/domingo-multidao-lota-cenaculo-doespirito-santo-no-amazonas-9174.html >. Acesso em: 23. fev. 2013.
} 


\section{Referenciais}

\section{Fontes primárias}

BÍBLIA. Português. Bíblia sagrada. Tradução por João Ferreira de Almeida. Rio de Janeiro: Juerp/IBB, 1998.

BLOG BISPO MACEDO. Blog oficial do Bispo Edir Macedo. Disponível em:

$<$ http://www.bispomacedo.com.br/> Acesso em: 20. Jan. 2014.

BLOG BISPO RENATO CARDOSO. Blog oficial do Bispo Renato Cardoso. Disponível em: <http://www.renatocardoso.com/blog/> Acesso em: 20. Jan. 2014.

PORTAL UNIVERSAL. Site oficial da Igreja Universal do Reino de Deus. Disponível em:

<http://www.universal.org/> Acesso em: 20. jan. 2014.

\section{Referências bibliográficas}

ALBUQUERQUE, E. B. Historiografia e Religião. Revista Nures: Núcleo de Estudos Religião e Sociedade- Pontifícia Universidade Católica -SP, $n^{\circ}$ 5, Janeiro/Abril 2007. Disponível em: <http://www.pucsp.br/revistanures $>$ Acesso em: 10. Jan. 2014.

ALMEIDA, R. Guerra das possessões. In: ORO, A. P.; CORTEN, A.; Jean-Pierre D. (Org.) Igreja Universal do Reino de Deus: os novos conquistadores da fé. São Paulo: Paulinas, 2003. BARROS, J. A. A Nova História Cultural: considerações sobre o seu universo conceitual e seus diálogos com outros campos históricos. Cadernos de História, Belo Horizonte, v.12, n. 16, $1^{\circ}$ sem. 2011.

. Fernand Braudel e a geração dos Annales. Revista Eletrônica História em Reflexão: Vol. 6 n. 11 - UFGD - Dourados jan/jun 2012.

BELlotTI, K. K. Mídia, Religião e História Cultural. Rever - Revista de Estudos da Religião. $\mathrm{n}^{\mathrm{o}}$ 4. - PUC - São Paulo, 2004. Disponível em: <www.pucsp.br/rever/rv4 2004/p bellotti.pdf > Acesso em: 20. mar. 2014.

BLOCH, M. Apologia da História ou o ofício de historiador. Rio de Janeiro: Zahar, 2001. BURKE, P. O que é História Cultural?. Rio de Janeiro: Zahar, 2005.

CAMPOS, L. S. Teatro, templo e mercado: uma análise da organização, rituais, marketing e eficácia comunicativa de um empreendimento neopentecostal - Igreja Universal do Reino de Deus. Petrópolis/ São Bernardo do Campo: Vozes/ IMES, 1997/1996.

FONSECA, A. B. Igreja Universal: um império midiático, In: ORO, A. P.; CORTEN, A.; JeanPierre D. (org.) Igreja Universal do Reino de Deus: os novos conquistadores da fé. São Paulo: Paulinas, 2003.

FOUCAULT, M. Sexualidade e solidão. In: MOTTA, M. B. (Org.) Michel Foucault: ética, sexualidade, política. Rio de Janeiro: Forense Universitária, 2004. (Coleção Ditos e Escritos V) FRESTON, Paul. Protestantes e política no Brasil: da Constituinte ao Impeachment. 1993. Tese de doutorado em Sociologia - UNICAMP, Campinas.

LE GOFF, Jacques. A História Nova. $4^{\mathrm{a}}$ ed. São Paulo: Martins Fontes, 2001.

MARIANO, R. Neopentecostais: sociologia do novo pentecostalismo no Brasil. $2^{\mathrm{a}}$ ed. São Paulo: Loyola, 1999.

PESAVENTO, S. J. História \& história cultural. 2a ed. Belo Horizonte: Autêntica, 2005.

POL-DROIT, R. Michel Foucault: entrevistas. São Paulo: Graal, 2006.

REIS, J. C. Escola dos Annales: a inovação em história. São Paulo: Paz e Terra, 2000.

SANCHONETE, C. Religião 2.0: um novo conceito. Transcrição da entrevista concedida à rádio Unisinos-RS em 29 março de 2011. p. 03. Disponível em: $<$ http://www.ihu.unisinos.br/entrevistas/41833-religiao-20-um-novo-conceito-entrevistaespecial-com-carlos-sanchotene> Acesso em: 30. março. 2014. 
TAVOLARO, D. O Bispo - Biografia de Edir Macedo. Rio de Janeiro: Larousse, 2007.

VAINFAS, R. História cultural e historiografia brasileira. Revista de História: Questões \& Debates, UFPR, Curitiba, n. 50, p. 217-235, jan./jun. 2009. Disponível em: $<$ http://ojs.c3sl.ufpr.br/ojs/index.php/historia/article/viewArticle/15676> Acesso em: 10 jul. 2014.

VEYNE, Paul. Como se escreve a história e Foucault revoluciona a história. $3^{\mathrm{a}}$ ed. Brasília: Editora Universidade de Brasília, 1995.

Foucault: seu pensamento, sua pessoa. Rio de Janeiro: Civilização Brasileira, 2011.

Recebido: 04/02/2014

Received: 02/04/2014

Aprovado: 19/07/2014

Approved: 07/19/2014 